\title{
On the Influence of Electrical Discharge Drilling Parameters and Performance Measures of Inconel 718 Superalloy - a Study
}

\author{
Jayaraj JEEVAMALAR*, Sundaresan RAMABALAN**, Jayaraj JANCIRANI*** \\ *E.G.S. Pillay Engineering College, Nagapattinam, Tamilnadu, India, E-mail: J.Jeevamalar@gmail.com \\ **E.G.S. Pillay Engineering College, Nagapattinam, Tamilnadu, India, E-mail: cadsrb@gmail.com \\ ***MIT Campus, Anna University, Chennai, Tamilnadu, India, E-mail: jancijeyaraj@yahoo.com \\ crossref http://dx.doi.org/10.5755/j02.mech.25444
}

\section{Introduction}

Presently, with gamut of technologies available still the manufacturing industries are beleaguered by significant challenges from hard-to-cut materials like superalloys, ceramics, stainless steels, brass, carbides and fiberreinforced composites along with exact design requirements (i.e., superior surface finish, high precision, versatility, high strength, intricate geometrical properties, low thermal expansion and robustness, etc.) and economical operation. Conventional Machining Processes (CMP) requires cutting tools that are tougher than the workpiece and require direct interaction between the workpieces. These features of CMP lead to hardships in handling hard and fragile materials.

Unconventional advanced manufacturing processes (UMP) are an ensemble of material removal techniques involving mechanical, chemical, electrical or thermal energy or application of hybrid energies to machine difficult geometries along with superior surface finish. Unconventional Machining Processes are used where CMPs are not practicable, reasonable or cost-effective. With the proliferation of industrial and technological innovations in the domain of manufacturing and material sciences, every industry, including aerospace, automobile, biotechnology, nuclear, army, chemical, locomotive, and foundries aims for higher production efficiency, higher accuracy and precision, greater surface finish and close tolerances in all their applications. Unconventional machining processes when implemented properly provide limitless benefits over CMPs.

Inconel 718 is a superalloy based on nickel chromium that contains large amounts of iron, niobium and molybdenum, together with smaller quantity of titanium and aluminium. It is a precipitation-hardened alloy and pigeonholed as hard-to-drill material since it has superior strength and hardness (38 HRC) and good tensile strength $(180 \mathrm{ksi})$. It has excellent oxidation resistance $\left(983^{\circ} \mathrm{C}\right)$ and high creep-rupture strength $\left(700^{\circ} \mathrm{C}\right)$. These properties impose some technical hitches during drilling. Alternatively, these hitches were accredited to its competence to preserve its rigidity at a very high temperature and appropriate for the hot working environment. The creation of complex contours in Inconel 718 along with decent drilling performance and geometric accuracy are not viable by CMP and require advanced techniques to achieve the best finish of the machined surface. Inconel 718 has extensive applications in spacecraft and gas turbines, reciprocating engines, components of heat treating equipment, nuclear pressurized water reactors, and motor shafts for the submersible well pump, chemical processing, pressure vessels, and petrochemical industries.

In spite of the enormous majority of research activities have focused in recent years to drill hard-to-cut materials, still the following issues are not resolved for drilling of superalloys:

1. shorter tool life due to their hardening and erosion properties;

2. the workpiece temperature increases up to its boiling temperature while drilling;

3. built-up-edge is often formed on the electrode owing to an elevated temperature across tool and workpiece material [ $1-3]$;

4. metallurgical impairment to the drilling parts owing to excessive forces, which gives elevated work inurement, surface cracking and deformation.

Of late, many researchers have investigated the drilling performance of superalloy by considering different input parameters. Yet, the challenge to measure the performance regarding the drilling technique of Inconel 718 is continuing. This research is mainly to increase performance, product quality and the overall economy of the drilling process on Inconel 718 using Tungsten powder mixed dielectric and Copper $(\mathrm{Cu})$ electrode.

After a comprehensive investigation of the previous research works related to the Electrical Discharge Drilling (EDD) process of superalloys, it is clear that the influence of the rotating electrode with W-powder assorted with kerosene has not been described in the literature sufficiently [4 - 15]. Moreover, very few investigations have been reported on the evaluation of Surface Roughness (SR) of the Inconel 718 through EDD process. The research question of this present study is to explore the effects of input variables like peak current $I_{p}$, pulse-on time $T_{o n}$ and pulse-off time $T_{\text {off }}$ on performance metrics such as Material Removal Rate (MRR) and Surface Roughness (SR) while drilling on Inconel 718 under Tungsten (W) powder suspended kerosene with a rotating hollow Copper tool.

The experiments have been done based on $L_{27}$ Orthogonal Array (OA) and the effects had been validated by using Artificial Neural Networks (ANN) technique and the results were confirmed by Artificial Neural Networks (ANN) technique. To evaluate the property of the machined surfaces, Scanning Electron Microscope observations were carried out. To the best of our knowledge, the literature shows that no researcher realizes surface characterization of the drilled workpieces with W-powder suspended EDD. Hence, this shows the uniqueness of this work, it is much important to investigate and characterize the surface of the drilled Inconel 718 workpiece with 
W-powder suspended into the dielectric medium.

\section{Materials and methods}

Experimentation to select optimal processing variables is generally carried out in two steps: i) Preliminary study and ii) main experimentation. A preliminary study was conducted to classify the major contributing factors and their level to check each variable's impact on the drill response before performing the main experiments.

\subsection{Preliminary study}

Inconel 718 rod of diameter $25 \mathrm{~mm}$ was made into slices of $3 \mathrm{~mm}$ thick disc by wire-EDM. In this study, all the trials have been conducted using a tubular Copper electrode ( $99.9 \%$ purity) and high-pressure dielectric fluid is supplied through it into the Inter Electrode Gap (IEG). Kerosene was chosen as a dielectric fluid in this research and $\mathrm{W}$-powder (3-5 micron) was selected as an additive and blended with kerosene in a concentration of $3 \mathrm{~g} / \mathrm{l}$. Three important controllable parameters (i.e. $I_{p}, T_{o n}$, and $\left.T_{\text {off }}\right)$ were selected and varied to predict their impact on the output responses. The peak current was selected at $10 \mathrm{~A}$, $12.5 \mathrm{~A}$ and $15 \mathrm{~A}$ for various pulse-on time $(500 \mu \mathrm{s}$, $1000 \mu \mathrm{s}$, and $1500 \mu \mathrm{s})$ and pulse-off time $(200 \mu \mathrm{s}, 500 \mu \mathrm{s}$, and $800 \mu \mathrm{s})$.

MRR and SR were identified as the output responses for this study. MRR was measured as weight reduction per unit time on the workpiece. In order to calculate MRR, the workpiece was weighed during the drilling operation by means of a precision self-calibrating; electronic weighing scale and the difference gives the mass of workpiece removed. Higher the MRR in the drilling process better is the performance.

The difference in weight was then converted to vo lumetric loss using Eq. (1).

$$
\operatorname{MRR}(g . / \mathrm{min})=\frac{\text { Mass of workpiece removed }}{\text { Time of machining }} .
$$

SR is an important performance measure for drilling processes that influence product quality and cost. It has a strong influence on fatigue, the surface finish, strength and tool wear resistance. Reduced value of SR in the EDD results in better output response. SR was measured using the Surface Roughness Tester, SE 300 model.

\subsection{Main experimentation}

The entire experimental work was accomplished on a commercial type ELEKTRA M100 die-sinking EDM machine. Fig. 1 shows the EDM machine used in this study. A tank was designed and made using a steel sheet size of $330 \mathrm{~mm} \times 180 \mathrm{~mm} \times 187 \mathrm{~mm}$ and $3 \mathrm{~mm}$ thickness. The capacity of the tank is around 9 litres, after the volume of the fixture and other accessories is deducted. For the blending of powder particles, a motorized stirrer was provided which was rotated at 1400 RPM.

Since there are three levels of selected drilling factors, the $L_{27}\left(3^{3}\right)$ Orthogonal Array (OA) has been chosen as the most appropriate OA for main experiment. To decrease the consequence of noise, all the 27 trials were repeated three times with the same set of drilling parame- ters in random order.

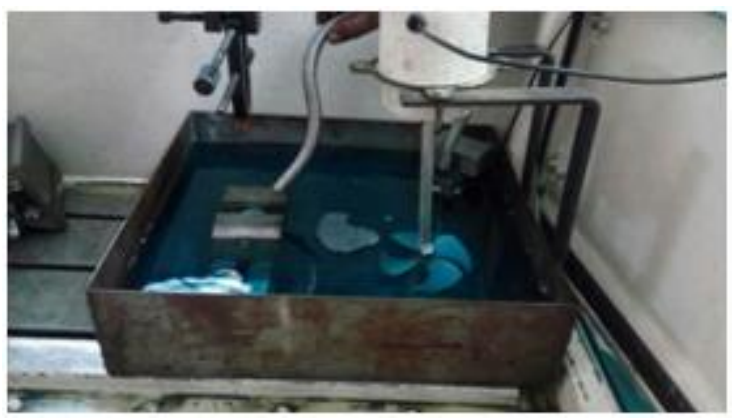

Fig. 1ELEKTRA M100 EDM setup

The values of $I_{p}, T_{o n}$ and $T_{\text {off }}$ was varied from the machine control panel. The obtained average MRR and SR for all the 27 experiments are furnished in Table 1. The results obtained were examined to determine the optimum combination of input for each response, Percentage Contribution (PC) and the significance of each parameter using ANOVA and also machined workpiece surface characteristics. MINITAB 18 was used for assigning the parameters to the array.

Table 1

$L_{27}$ Experimental design with response variables

\begin{tabular}{|c|c|c|c|c|c|}
\hline $\begin{array}{c}\text { Exp. } \\
\text { No. }\end{array}$ & $I_{p}, \mathrm{~A}$ & $T_{\text {on }}, \mu \mathrm{s}$ & $T_{\text {off }, \mu \mathrm{s}}$ & $\begin{array}{c}\text { Mean MRR, } \\
\mathrm{g} / \mathrm{min} .\end{array}$ & $\begin{array}{c}\text { Mean SR, } \\
\mu \mathrm{m}\end{array}$ \\
\hline 1 & 10 & 500 & 200 & 0.134 & 3.601 \\
\hline 2 & 10 & 500 & 500 & 0.260 & 3.344 \\
\hline 3 & 10 & 500 & 800 & 0.406 & 3.218 \\
\hline 4 & 10 & 1000 & 200 & 0.334 & 2.723 \\
\hline 5 & 10 & 1000 & 500 & 0.294 & 2.594 \\
\hline 6 & 10 & 1000 & 800 & 0.300 & 2.569 \\
\hline 7 & 10 & 1500 & 200 & 0.384 & 2.759 \\
\hline 8 & 10 & 1500 & 500 & 0.262 & 2.527 \\
\hline 9 & 10 & 1500 & 800 & 0.300 & 2.508 \\
\hline 10 & 12.5 & 500 & 200 & 0.344 & 3.546 \\
\hline 11 & 12.5 & 500 & 500 & 0.298 & 3.252 \\
\hline 12 & 12.5 & 500 & 800 & 0.302 & 3.126 \\
\hline 13 & 12.5 & 1000 & 200 & 0.318 & 2.957 \\
\hline 14 & 12.5 & 1000 & 500 & 0.308 & 2.788 \\
\hline 15 & 12.5 & 1000 & 800 & 0.296 & 2.652 \\
\hline 16 & 12.5 & 1500 & 200 & 0.562 & 2.689 \\
\hline 17 & 12.5 & 1500 & 500 & 0.294 & 2.548 \\
\hline 18 & 12.5 & 1500 & 800 & 0.302 & 2.512 \\
\hline 19 & 15 & 500 & 200 & 0.624 & 4.578 \\
\hline 20 & 15 & 500 & 500 & 0.592 & 4.127 \\
\hline 21 & 15 & 500 & 800 & 0.576 & 3.648 \\
\hline 22 & 15 & 1000 & 200 & 0.774 & 3.377 \\
\hline 23 & 15 & 1000 & 500 & 0.682 & 3.224 \\
\hline 24 & 15 & 1000 & 800 & 0.492 & 2.847 \\
\hline 25 & 15 & 1500 & 200 & 0.872 & 3.248 \\
\hline 26 & 15 & 1500 & 500 & 0.648 & 2.912 \\
\hline 27 & 15 & 1500 & 800 & 0.346 & 2.588 \\
\hline & & & & & \\
\hline
\end{tabular}

After drilling, the machined surface characteristics were studied using a high-imaging Scanning Electron Microscope paired with an Energy Dispersive Spectrometer (SEM-EDS), which is widely used for surface analysis.

\section{Results and discussion}

The goal of this study is to find the combined effect of factors that will maximize the MRR and minimize SR. For this, a second-order model can be constructed effi- 
ciently using an $L_{27}$ orthogonal array. This OA makes a correlation between drilling parameters and performance measures by considering the benefit of output responses. The experiments based on selected OA were carried out for various levels of input parameters and response values were recorded.

\subsection{Analysis of variance}

\subsubsection{ANOVA for MRR}

ANOVA tests for individuals, the two-way interaction and the quadratic effect of drilling factors for MRR have been carried out. By using a significance analysis, the most significant input factors, as well as the most significant pairs of drilling factors could be determined. Consequently, experiments were conducted based on partial factorial plans because of the better elucidations which could be done. Higher F-Value and lesser P-Value indicates that the higher significance of input parameters. In this analysis, If $\mathrm{P}-$ Value $=0.000 \%$, then the influence of the parameter is most significant. If P-Value $\leq 5 \%$ (i.e. $95 \%$ confidence level), then the influence of the parameter is significant. If the P-Value $>5 \%$, then it is considered that the parameter is not significant. Percentage Contribution (PC) is defined as the degree of importance of the input factors on the output response. The individual, interaction and quadratic effect of all the factors with their significance are summarized in the following Table 2.

Table 2

ANOVA for MRR

\begin{tabular}{|c|c|c|c|c|c|c|c|}
\hline Source & DF & $\begin{array}{l}\text { Seq } \\
\text { SS }\end{array}$ & $\begin{array}{l}\text { Adj } \\
\text { SS }\end{array}$ & $\begin{array}{l}\text { Adj } \\
\text { MS }\end{array}$ & $\begin{array}{c}\text { P- } \\
\text { Value }\end{array}$ & $\mathrm{PC}, \%$ & $\begin{array}{l}\text { Signifi- } \\
\text { cance }\end{array}$ \\
\hline$I_{p}$ & 1 & 0.478 & 0.049 & 0.049 & 0.000 & 55.2 & $* *$ \\
\hline$T_{\text {on }}$ & 1 & 0.010 & 0.010 & 0.010 & 0.076 & 1.21 & $\mathrm{X}$ \\
\hline$T_{\text {off }}$ & 1 & 0.058 & 0.050 & 0.050 & 0.000 & 6.76 & $* *$ \\
\hline$I_{p} * I_{p}$ & 1 & 0.092 & 0.092 & 0.092 & 0.000 & 10.6 & $* *$ \\
\hline$T_{o n} * T_{o n}$ & 1 & 0.000 & 0.000 & 0.000 & 0.816 & 0.02 & $\mathrm{X}$ \\
\hline$T_{\text {off }} * T_{\text {off }}$ & 1 & 0.003 & 0.003 & 0.003 & 0.321 & 0.33 & $\mathrm{X}$ \\
\hline$I_{p} * T_{o n}$ & 1 & 0.000 & 0.000 & 0.000 & 0.694 & 0.05 & $X$ \\
\hline$I_{p} * T_{\text {off }}$ & 1 & 0.085 & 0.085 & 0.085 & 0.000 & 9.83 & $* *$ \\
\hline$T_{o n} * T_{o f f}$ & 1 & 0.092 & 0.092 & 0.092 & 0.000 & 10.6 & $* *$ \\
\hline Error & 17 & 0.046 & 0.046 & 0.003 & - & 5.29 & - \\
\hline Total & 26 & 0.865 & - & - & - & 100 & - \\
\hline \multicolumn{3}{|c|}{$S=0.0518863$} & \multicolumn{2}{|c|}{$R-s q=94.71 \%$} & \multicolumn{3}{|c|}{$R-s q(\operatorname{adj})=91.91 \%$} \\
\hline \multicolumn{3}{|c|}{${ }^{* *}$ Most Significant } & \multicolumn{2}{|c|}{ * Significant } & \multicolumn{3}{|c|}{$\mathrm{x}$ Not Significant } \\
\hline
\end{tabular}

The outcomes of ANOVA reveal that the linear effect of peak current (i.e. $I_{p}$ ), the quadratic effect of $I_{p}$ (i.e. $I_{p^{*}} I_{p}$ ), the two-way interaction of $T_{o n}$ with $T_{\text {off }}$ (i.e. $\left.T_{o n} * T_{o f f}\right)$, the two-way interaction of $I_{p}$ with $T_{\text {off }}\left(\right.$ i.e. $\left.I_{p} * T_{o f f}\right)$ and the linear effect of $T_{\text {off }}$ are most significant factors with PC of $55.20 \%, 10.66 \%, 10.66 \%, 9.83 \%$ and $6.76 \%$ respectively. The other model terms are not as significant as related to the MRR. The model summary suggested that the model significantly affects its performance analysis of MRR. The value of $R-s q$ estimated for this model is $94.71 \%$ and it is reasonably closer to $100 \%$, which is acceptable. The standard deviation of error $S$ in modelling is 0.0518863 . The value of $R-{ }_{-s q}(a d j)$ equals to $91.91 \%$, which shows the number of predictors in the model. Both the value implies that the data are fitted well and gives an admirable description of the correlation between the drilling parameters and the output SR. The correlation among input factors and MRR was obtained by the regression model. After excluding the insignificant terms, the metal removal rate can be expressed in Eq. (2):

$$
\begin{aligned}
& \text { MRR }=1.644-0.3699 * I_{p}+0.001556 * T_{o f f}+ \\
& +0.01984 * I_{p} * I_{p}-0.000112 * I_{p} * T_{o f f}- \\
& -0.000001 * T_{o n} * T_{o f f} .
\end{aligned}
$$

\subsubsection{ANOVA for SR}

For verifying the competence of the developed model for SR, the procedure was repeated for a 95\% confidence level. Lesser P-Value and higher F-Value implies the higher significance of the input factors.

ANOVA for SR

Table 3

\begin{tabular}{|c|c|c|c|c|c|c|c|}
\hline Source & DF & $\begin{array}{c}\text { Seq } \\
\text { SS }\end{array}$ & $\begin{array}{c}\text { Adj } \\
\text { SS }\end{array}$ & $\begin{array}{c}\text { Adj } \\
\text { MS }\end{array}$ & P-Value & PC, $\%$ & $\begin{array}{c}\text { Signifi- } \\
\text { cance }\end{array}$ \\
\hline$I_{p}$ & 1 & 1.23 & 0.16 & 0.16 & 0.00 & 17.2 & $*$ \\
\hline$T_{\text {on }}$ & 1 & 3.68 & 0.28 & 0.285 & 0.000 & 51.8 & $* *$ \\
\hline$T_{\text {off }}$ & 1 & 0.80 & 0.00 & 0.005 & 0.568 & 11.3 & X \\
\hline$I_{p} * I_{p}$ & 1 & 0.33 & 0.33 & 0.335 & 0.000 & 4.70 & $* *$ \\
\hline$T_{\text {on }} * T_{\text {on }}$ & 1 & 0.51 & 0.51 & 0.514 & 0.000 & 7.22 & $* *$ \\
\hline$T_{\text {off }} T_{\text {off }}$ & 1 & 0.00 & 0.00 & 0.005 & 0.555 & 0.07 & X \\
\hline$I_{p} * T_{\text {on }}$ & 1 & 0.12 & 0.127 & 0.127 & 0.007 & 1.79 & $*$ \\
\hline$I_{p} * T_{\text {off }}$ & 1 & 0.14 & 0.148 & 0.148 & 0.004 & 2.08 & $*$ \\
\hline$T_{\text {on }} * T_{\text {off }}$ & 1 & 0.03 & 0.035 & 0.035 & 0.127 & 0.49 & X \\
\hline Error & 17 & 0.22 & 0.229 & 0.013 & - & 3.21 & - \\
\hline Total & 26 & 7.11 & - & - & - & 100 & - \\
\hline$S=0.116011$ & $R-s q=96.79 \%$ & $R-s q(a d j)=95.08 \%$ \\
\hline
\end{tabular}

Table 3 shows the individual, interaction and quadratic effect of all the input factors with their significance on SR. The linear effect of $T_{o n}(51.83 \%)$ is the most significant factor followed by the quadratic effect of $T_{o n}$ $(7.22 \%)$, the quadratic effect of $I_{p}(4.70 \%)$. The linear effect of $I_{p}(17.28 \%)$, the two-way interaction of $I_{p}$ with $T_{\text {off }}$ $(2.08 \%)$, and the two-way interaction of $I_{p}$ with $T_{o n}$ $(1.79 \%)$ are significant. $T_{\text {off }}$ is not a significant parameter. From Table 3, the value of $R-s q$ was estimated for this model is $96.79 \%$ and it is acceptable. The standard deviation of error $S$ in modelling is 0.116011 . The value of $R$-sq $(a d j)$ equals to $95.08 \%$, which indicates the number of predictors in the model. Both the values imply that the data are fitted well and provides a commendable clarification of the relationship between the drilling parameters and the output SR. From the regression analysis, a mathematical model for SR was derived and given in Eq. (3).

$$
\begin{aligned}
& \mathrm{SR}=8.01341-0.6839 * I_{p}-0.002396 * T_{o n}+ \\
& +0.03780 * I_{p} * I_{p}+0.000001 * T_{o n} * T_{o n} \\
& -0.000082 * I_{p} * T_{o n}-0.000148 * I_{p} * T_{o f f} .
\end{aligned}
$$

\subsection{ANN Modelling}

Recently, ANNs have become a prevalent technique in the modelling of manufacturing-related complex problems due to their ability to analyze and interpolate relations amongst input and output parameters [16]. A typical ANN model of any processes accomplished in three 
phases: training, testing, and validation. ANN excludes the restrictions of traditional methods by extracting the required information from input data [17]. Based on the structure of ANN in a problem solution, they can be classified into two types: i) Feedback Neural Networks (FBNN) and ii) Feed Forward Neural Networks (FFNN). In the FFNN model, the signals propagate from the input layer to the output layer in order. Alternatively, in FBNN computations may flow from the output nodes to the input nodes.

ANN was configured with various layers, and therefore named as multilayer ANNs. Multilayer perception ANN comprises input, hidden and output layers. The input node denotes an input parameter, while the output neurons provide the dependent response. Hidden (Middle) layers are used to implement nonlinear transformations on the input space and are used for computation purposes. A single hidden layer was implemented in this research. The number of neurons in the middle layer was identified by a series of network configurations. Using the MATLAB NN toolbox, the multilayer preceptor trained back-propagation algorithm has been applied for predicting MRR and SR. A total of 27 trials was conducted to identify variations in MRR due to the different level setting of input factors of the $I_{p}, T_{o n}$, and $T_{o f f}$. The data used for training the ANN model are tabulated in Table 4.

Table 4

ANN model data

\begin{tabular}{|l|l|}
\hline \multicolumn{1}{|c|}{ Name } & \multicolumn{1}{c|}{ ANN model for PMEDD } \\
\hline Network type & FFBP model \\
\hline No of hidden layers & 6 \\
\hline Transfer function & PURELIN \\
\hline Training function & TRAINLM \\
\hline Learning function & LEARNGDM \\
\hline Performance function & Mean square error \\
\hline Number of neurons & 6 \\
\hline Sum of squared error & 0.072739 \\
\hline Number of epochs & 15 \\
\hline Validation checks & 6 \\
\hline Learning factor & 0.6 \\
\hline
\end{tabular}

ANN has been implemented with the LevenbergMarquardt back propagation algorithm (TRAINLM). The input layer consists of 3 nodes for three decision variables of the study (i.e. $I_{p}, T_{o n}$, and $T_{\text {off }}$ ). The hidden layer comprises 6 nodes and the output layer consists of two nodes for MRR and SR as shown in Fig. 2.

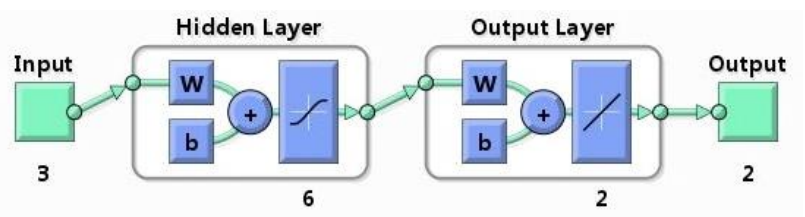

Fig. 2 ANN training module

The performance and regression graphs of output responses obtained for EDD are shown in Figs. 3 and 4 correspondingly. Successful training was performed after 15 iterations with an MSE error of 0.072739 with 6 validating checks. The R-value for the training data was at 0.99997 and the R-value for the testing data was 0.95735 .

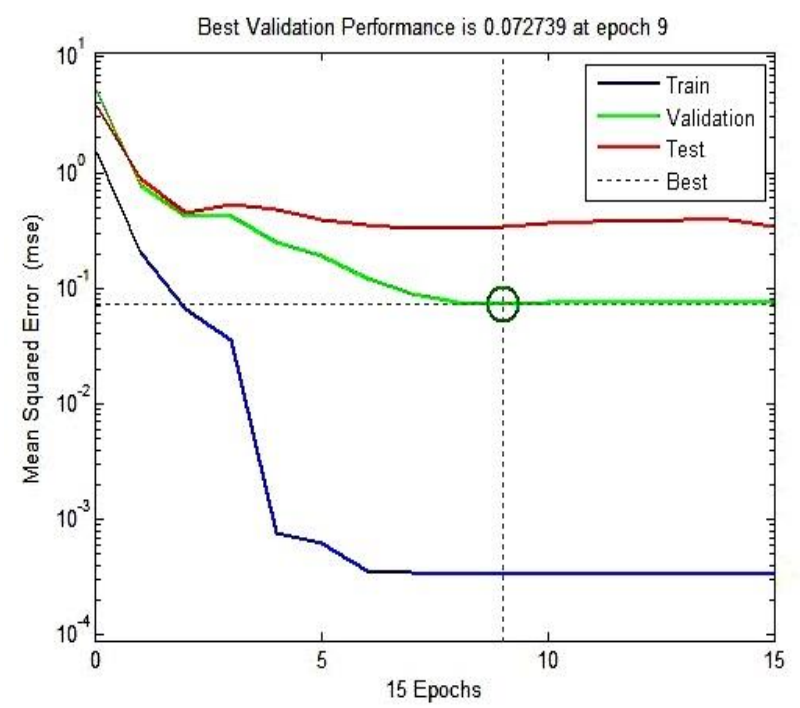

Fig. 3 Performance curve
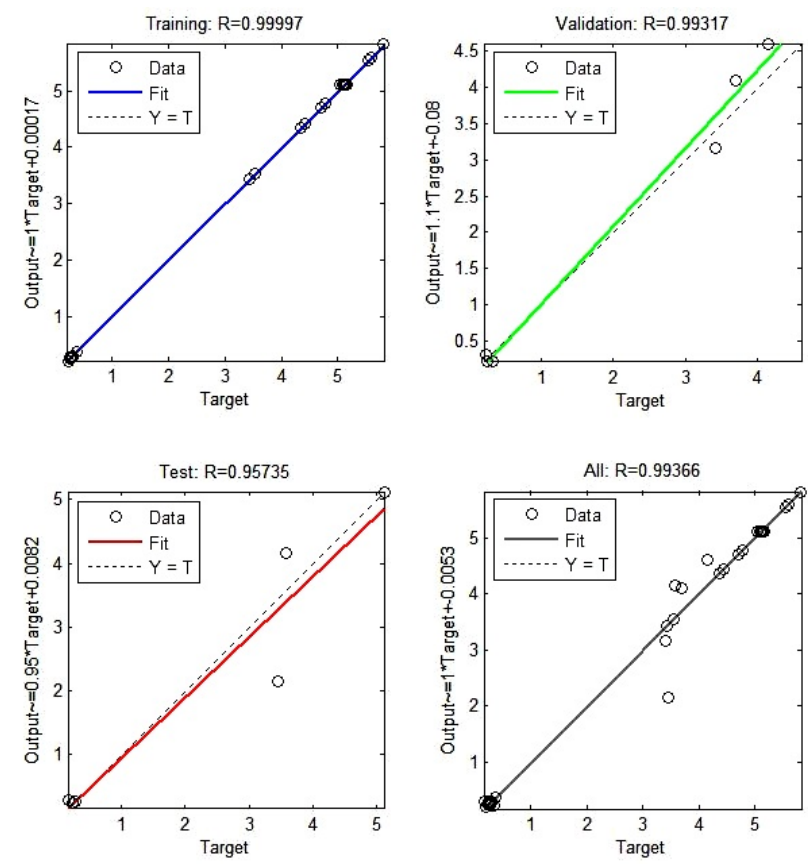

Fig. 4 Regression plots

\subsubsection{Verification of the trained networks}

Table 5 compares the experimental results and ANN predictions with respect to MRR and SR for Wpowder mixed EDD with the rotary tool. Results from the ANN have been found to show excellent consistency with experimental observations around the range.

Table 5

Comparison of experimental and ANN Modelling

\begin{tabular}{|c|c|c|c|c|c|c|}
\hline \multirow{2}{*}{$\begin{array}{c}\text { Exp. } \\
\text { No. }\end{array}$} & \multicolumn{2}{|c|}{ MRR, g/min } & \multirow{2}{*}{ Error } & \multicolumn{2}{c|}{ SR, $\mu \mathrm{m}$} & \multirow{2}{*}{ Error } \\
\cline { 2 - 3 } \cline { 5 - 6 } & Exp. & Pred. & & Exp. & Pred. & \\
\hline 1 & 0.134 & 0.146 & -0.012 & 3.601 & 3.475 & 0.126 \\
\hline 2 & 0.260 & 0.260 & 0.000 & 3.344 & 3.342 & 0.002 \\
\hline 3 & 0.406 & 0.387 & 0.019 & 3.218 & 3.217 & 0.001 \\
\hline 4 & 0.334 & 0.332 & 0.002 & 2.723 & 2.51 & 0.213 \\
\hline 5 & 0.294 & 0.288 & 0.006 & 2.594 & 2.598 & -0.004 \\
\hline 6 & 0.300 & 0.326 & -0.026 & 2.569 & 2.569 & 0.000 \\
\hline 7 & 0.384 & 0.405 & -0.021 & 2.759 & 2.761 & -0.002 \\
\hline 8 & 0.262 & 0.278 & -0.016 & 2.527 & 2.317 & 0.210 \\
\hline 9 & 0.300 & 0.307 & -0.007 & 2.508 & 2.503 & 0.005 \\
\hline
\end{tabular}




\begin{tabular}{|c|c|c|c|c|c|c|}
\hline \multirow{2}{*}{$\begin{array}{c}\text { Exp. } \\
\text { No. }\end{array}$} & \multicolumn{2}{|c|}{ MRR, g/min } & \multirow{2}{*}{ Error } & \multicolumn{2}{|c|}{ SR, $\mu \mathrm{m}$} & \multirow{2}{*}{ Error } \\
\cline { 2 - 3 } \cline { 5 - 6 } & Exp. & Pred. & & Exp. & Pred. & \\
\hline 10 & 0.344 & 0.344 & 0.000 & 3.546 & 3.546 & 0.000 \\
\hline 11 & 0.298 & 0.309 & -0.011 & 3.252 & 3.248 & 0.004 \\
\hline 12 & 0.302 & 0.299 & 0.003 & 3.126 & 3.196 & -0.070 \\
\hline 13 & 0.318 & 0.318 & 0.000 & 2.957 & 2.957 & 0.000 \\
\hline 14 & 0.308 & 0.277 & 0.031 & 2.788 & 2.788 & 0.000 \\
\hline 15 & 0.296 & 0.327 & -0.031 & 2.652 & 2.639 & 0.013 \\
\hline 16 & 0.562 & 0.558 & 0.004 & 2.689 & 2.664 & 0.025 \\
\hline 17 & 0.294 & 0.307 & -0.013 & 2.548 & 2.505 & 0.043 \\
\hline 18 & 0.302 & 0.301 & 0.001 & 2.512 & 2.523 & -0.011 \\
\hline 19 & 0.624 & 0.639 & -0.015 & 4.578 & 4.575 & 0.003 \\
\hline 20 & 0.592 & 0.593 & -0.001 & 4.127 & 4.2 & -0.073 \\
\hline 21 & 0.576 & 0.544 & 0.032 & 3.648 & 3.66 & -0.012 \\
\hline 22 & 0.774 & 0.702 & 0.072 & 3.377 & 3.331 & 0.046 \\
\hline 23 & 0.682 & 0.694 & -0.012 & 3.224 & 3.332 & -0.104 \\
\hline 24 & 0.492 & 0.493 & -0.001 & 2.847 & 3.131 & -0.284 \\
\hline 25 & 0.872 & 0.865 & 0.007 & 3.248 & 3.333 & -0.08 \\
\hline 26 & 0.648 & 0.641 & 0.007 & 2.912 & 3.13 & -0.218 \\
\hline 27 & 0.346 & 0.347 & -0.001 & 2.588 & 2.83 & -0.242 \\
\hline
\end{tabular}

The results reveal that the maximum error is 0.112 for Experiment Number 22; the minimum error is 0.00 for Experiment Numbers 2, 10 and 13 for MRR. In the case of SR, the maximum error is 0.482 for Experiment Number 24; the minimum is 0.000 for Experiment Numbers $6,10,13$ and 14 .

\subsection{Influence of input parameters}

This session describes the influences of input process parameters at different levels. The influences were examined by generating surface plots using MINITAB release 18 software package. These maps are useful for establishing desirable response values and operating conditions.

\subsubsection{Influence of $I_{p}$ and $T_{o n}$ on MRR}

Fig. 5 shows a 3D surface relating to the influence of the controllable parameters $\left(I_{p}\right.$ and $\left.T_{o n}\right)$ on the quality characteristic of drilling (MRR). From this plot, the MRR increases with the increase of $I_{p}$. This is due to the dominant control of $I_{p}$ over the applied energy, i.e. with the increase in $I_{p}$ helps to create a robust arcing cycle, which produces higher thermal gradient, and the larger crater triggering more erosion and vaporization of the workpiece. For constant $T_{\text {off }}(500 \mu \mathrm{s})$, the MRR improved with $T_{o n}$.

To explore the effect of $I_{p}$ on MRR, $T_{o n}$ is varied while keeping $T_{\text {off }}$ constant as $500 \mu \mathrm{s}$. For the low $T_{\text {on }}$, the MRR is low and low spark energy is created in IEG due to inadequate heating of Inconel 718 and low pulse duration. At the high pulse time, MRR increased with increasing in $I_{p}$ because of the sufficient availability of spark energy and the heating temperature of the Inconel 718.

MRR is also better with an increase of $T_{o n}$. The MRR is directly associated to the intensity of electrical energy delivered during this $T_{o n}$ period. An Increase in $T_{o n}$ affects the MRR significantly. The additive in the insulating medium improves the MRR, as powder aids to bridge the IEG and increasing the likelihood of discharging; and also the superior conductivity of the additive helps to disperse the spark energy and generates a smaller volume of debris, which was easily removed, which finally reached the maximum MRR. The increase in $T_{o n}$ for all $I_{p}$ settings increases the MRR.

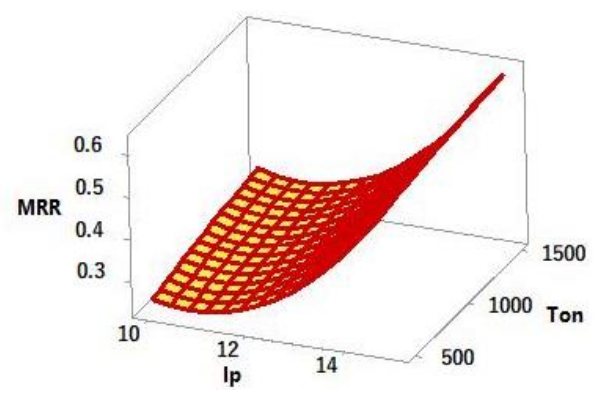

Hold Values

Toff 500

Fig. 5 Surface plot of $I_{p}$ and $T_{o n}$ on MRR at constant $T_{o f f}$

\subsubsection{Influence of $I_{p}$ and $T_{\text {off }}$ on MRR}

From the response surface plot shown in Figure 6, it is revealed that the MRR is increased by an improvement

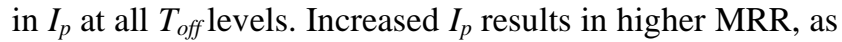
the discharge energy supplied is huge, increasing the rate of melting and vaporization of material and erosion of the larger crater area. During the tests, arcing was also observed when drilling with a higher $I_{p}$ and shorter $T_{\text {off }}$ values were performed. Therefore, MRR decreased due to unstable drilling.

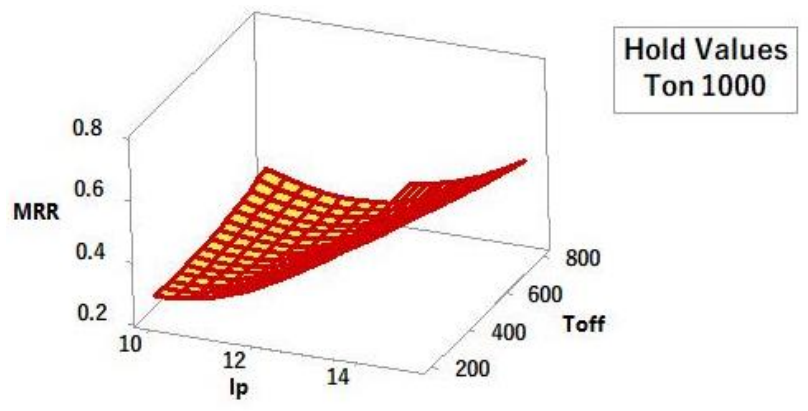

Fig. 6 Surface plot of $I_{p}$ and $T_{\text {off }}$ on MRR at constant $T_{o n}$

$T_{\text {off }}$ is the time required for the restoration of dielectric in IEG or deionization of an insulating medium at the end of every spark. For short $T_{\text {off }}(200 \mu \mathrm{s})$, MRR was less due to the fact that with shorter $T_{\text {off }}$ the possibility of arcing is very high, because the insulating fluid in IEG cannot be flushed away properly and the debris particles still remain in IEG, due to which MRR decreased. With a raise in $T_{o f f}$, better flushing of debris happens in IEG, results in an increase in MRR. This is attributed to the fact that an increase in $I_{p}$ leads to a steeper thermal gradient causing a higher rate of melting and evaporation as well as a greater MRR.

For short $T_{\text {off }}, \mathrm{MRR}$ is less due to the fact that with short pulse-off time the possibility of arcing is very high because the debris cannot be expelled from the drilling zone properly, which gets re-solidified on the surface contributing to improper sparking cycle and reduced MRR. With the boost in $T_{\text {off }}$, improved flushing of debris from the IEG and followed by an increase in MRR.

\subsubsection{Influence of $T_{\text {on }}$ and $T_{\text {off }}$ on MRR}

Fig. 7 shows a surface relating to the influence of the controllable parameters $\left(T_{o n}\right.$ and $\left.T_{\text {off }}\right)$ on the quality metrics of drilling (MRR). A similar trend is observed in this case also. The value of MRR gradually increased in $T_{o n}$ and decreased and decreased initially and afterwards increased with $T_{\text {off }}$. 


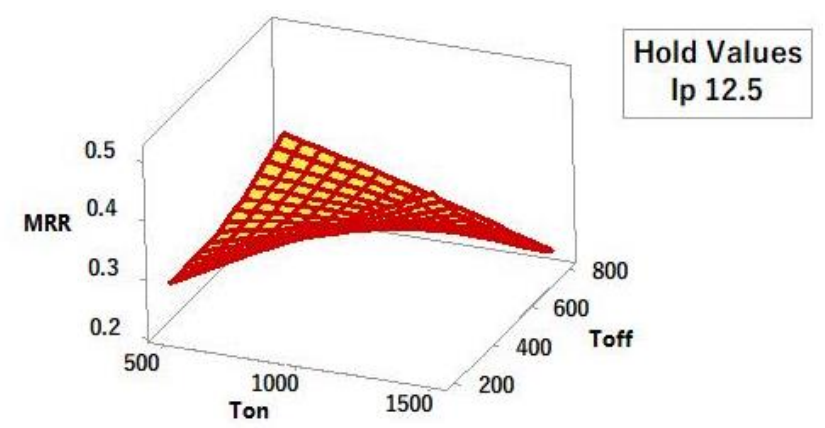

Fig. 7 Surface plot of $T_{o n}$ and $T_{\text {off }}$ at a constant $I_{p}$

\subsubsection{Influence of $I_{p}$ and $T_{o n}$ on SR}

Fig. 8 shows how the $I_{p}$ and $T_{o n}$ related to SR. With an increase in $I_{p}$ and $T_{o n}$, higher will be energy content per spark. When such a high energy spark hits the material, deeper pits will be created. These pits are responsible for SR. Many times the debris due to the high temperature gets solidified on the surface. Low $I_{p}$ and $T_{o n}$ created minimum SR that indicates good surface quality. Further, added W-powder particles expand and extend the plasma channel which enables easy removal of debris from the IEG. The powder particles cause the uniform distribution of spark energy in all directions. This results in shallow and small craters on the machining surfaces leading to reduction in surface roughness.

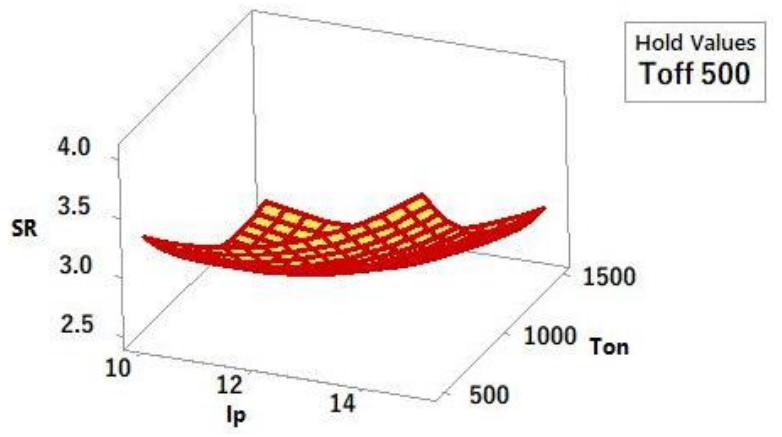

Fig. 8 Surface plot of $T_{o n}$ and $I_{p}$ at constant $T_{o f f}$

\subsubsection{Influence of $I_{p}$ and $T_{\text {off }}$ on SR}

Fig. 9 shows how the $I_{p}$ and $T_{\text {off }}$ related to surface roughness. With an increase in $I_{p}$ and $T_{\text {off }}$, higher will be energy content per spark. When such a high energy spark hits the material, deeper pits will be created. These pits are responsible for SR. Many times the debris due to the high temperature gets solidified on the surface. It is obvious from the figure that the short $T_{\text {off }}$ creates the higher frequency that produces low SR. With an increase of $T_{\text {off }}$ depreciates surface quality up to a certain level of the $T_{\text {on }}$ and further increase in pulse-off time offers good cooling effect of dielectric and sufficient time to enhance flushing of melted particles and debris from the inter-electrode gap. Therefore, long pulse-off time leads to low SR.

\subsubsection{Influence of $T_{\text {on }}$ and $T_{\text {off }}$ on SR}

Fig. 10 shows the outcome of $T_{\text {on }}$ and $T_{\text {off }}$ on SR. It can be seen that the value of SR linearly increased with increasing of $T_{\text {on }}$ and $T_{\text {off }}$, further increase in $T_{\text {on }}$ and $T_{\text {off }}$ the SR decreases. It is obvious from the figure that the short $T_{\text {off }}$ creates the higher frequency that produces low SR.
Similar to the previous case, with an increase of $T_{\text {off }}$ depreciates surface quality up to a certain level of the $T_{\text {on }}$ and further increase in pulse-off time offers good cooling effect of dielectric and sufficient time to enhance flushing of melted particles and debris from the inter-electrode gap. Therefore, long pulse-off time leads to low SR.

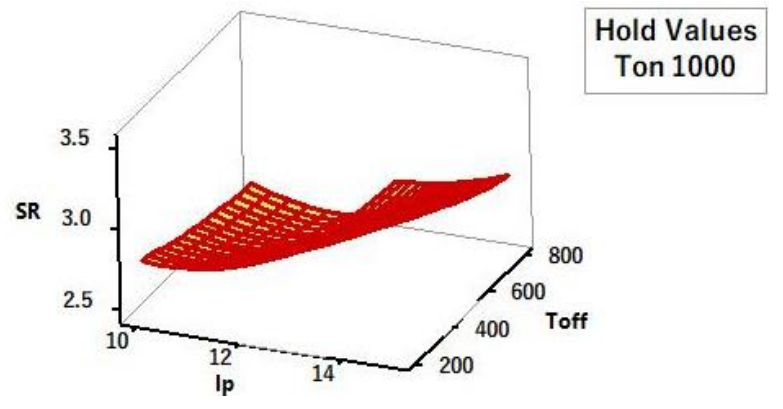

Fig. 9 Surface plot of $T_{o f f}$ and $I_{p}$ on SR at constant $T_{o n}$

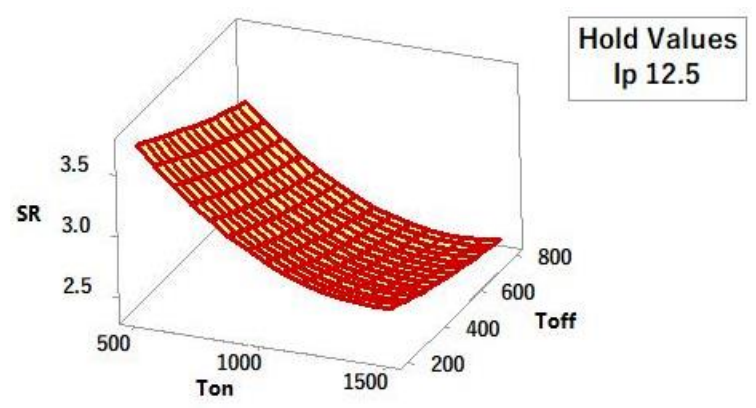

Fig. 10Surface plot of $T_{o n}$ and $T_{\text {off }}$ at constant $I_{p}$

\subsection{Surface topography analysis}

The micro-structural study of the drilled workpiece was conducted using a Scanning Electron Microscope paired with an Energy Dispersive Spectrometer (SEM-EDS). SEM micrographs were taken from the specimen with the zoom level of x250, x500 and x1000. After the drilling process, the machined workpiece surfaces had been sliced into small specimens to study the surface morphology of the machined specimens. The micrographs taken from the SEM analyzer were presented in Figs. 11-19. From the images, it is clear that $I_{p}$ and $T_{o n}$ influence the surface quality of drilled workpiece causing the creation of debris, larger craters, small cracks, and micro-pores.

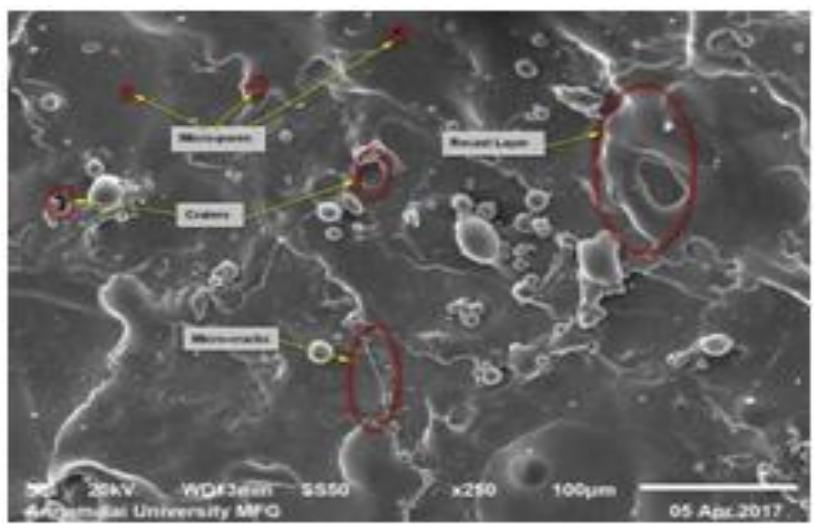

Fig. 11 SEM image for exp. no. 1

Fig. 11 shows the SEM micrographs of the machined workpiece for experiment number $1\left(I_{p}=10 \mathrm{~A}\right.$, $\left.T_{o n}=500 \mu \mathrm{s}, T_{o f f}=200 \mu \mathrm{s}\right)$. Due to low discharge energy at 
$10 \mathrm{~A}$ peak current and $500 \mu$ s pulse-on period, fewer small cracks and micro-pores were found on the surface. Traces of white oxide can also be observed due to the oxidation of $\mathrm{W}$-powder in the insulating fluid.

Figs. 12 and 13 show the SEM micrographs of the machined surface for Experiment number $5\left(I_{p}=10 \mathrm{~A}\right.$, $\left.T_{\text {on }}=1000 \mu \mathrm{s}, T_{o f f}=500 \mu \mathrm{s}\right)$ and Experiment number 9 $\left(I_{p}=10 \mathrm{~A}, T_{\text {on }}=1500 \mu \mathrm{s}, T_{\text {off }}=800 \mu \mathrm{s}\right)$ respectively. It is evident that the surface unevenness could be increased when drilling was carried out under high current and pulse duration. Deep craters, thick cracks, voids, pores, and small cracks can be realized on the surface of the specimen. The globules of debris and recast layer are also noted. The creation of small cracks is due to the changes in the constituents of thermal stresses, development of additional thermal energy. The existence of the debris on the specimen is owing to the migration of particles from $\mathrm{W}$-powder, workpiece, tool and insulating medium [18].

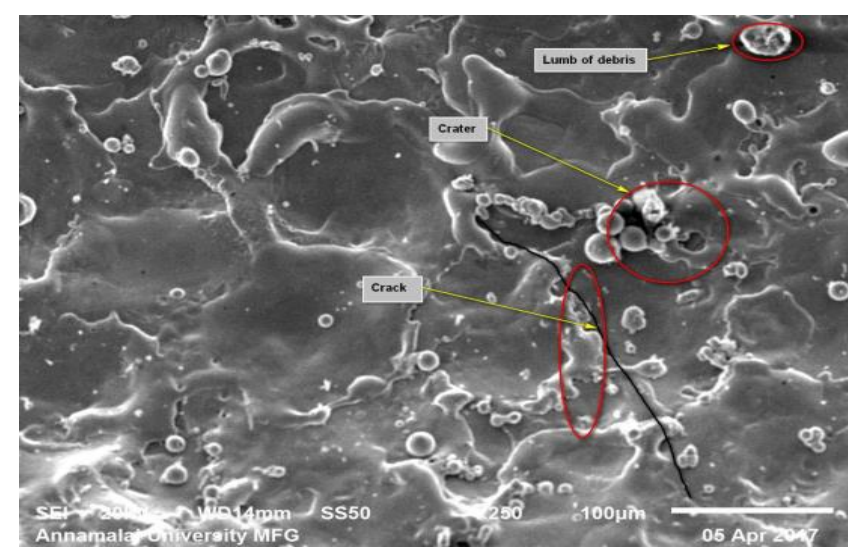

Fig. 12 SEM image for exp. no. 5

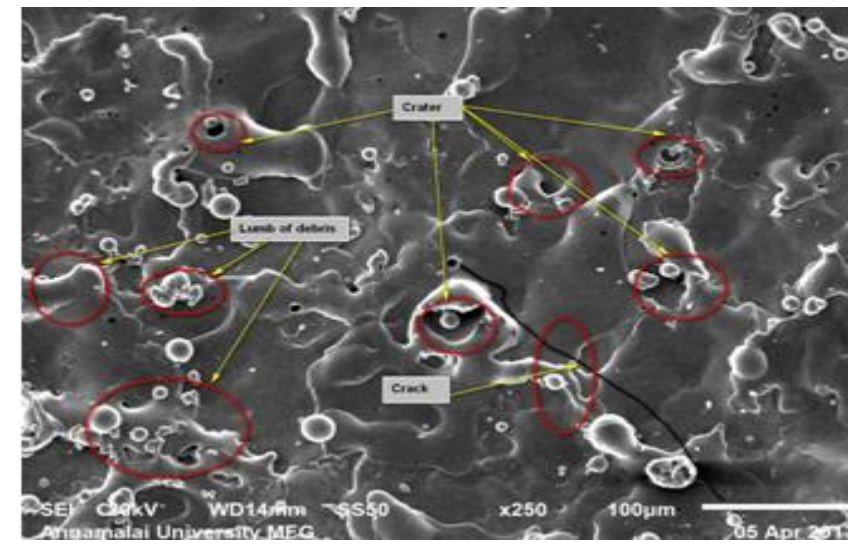

Fig. 13 SEM image for exp. no. 9

Figs. 14, 15 and 16 show the micrographs for Experiment Number. $10\left(I_{p}=12.5 \mathrm{~A}, T_{o n}=500 \mu \mathrm{s}, T_{o f f}=\right.$ $=200 \mu \mathrm{s})$, Experiment Number. $14\left(I_{p}=12.5 \mathrm{~A}, T_{o n}=1000\right.$ $\left.\mu \mathrm{s}, T_{\text {off }}=500 \mu \mathrm{s}\right)$ and Experiment Number. $18\left(I_{p}=12.5 \mathrm{~A}\right.$, $\left.T_{o n}=1500 \mu \mathrm{s}, T_{\text {off }}=800 \mu \mathrm{s}\right)$ respectively. It was clearly observed that in a rise in $I_{p}$ and $T_{o n}$, abnormalities on the surface also increase resulting in much thick and deeper craters. This is owing to the fact that as the $I_{p}$ rises with $T_{o n}$, the workpiece will melt with high thermal energy in the discharge channel. The higher $T_{o n}$ and $I_{p}$ led to large dispersive energy in the discharge channel which causes more vaporization and erosion of the workpiece. This results in the formation of larger craters on the surface [19].

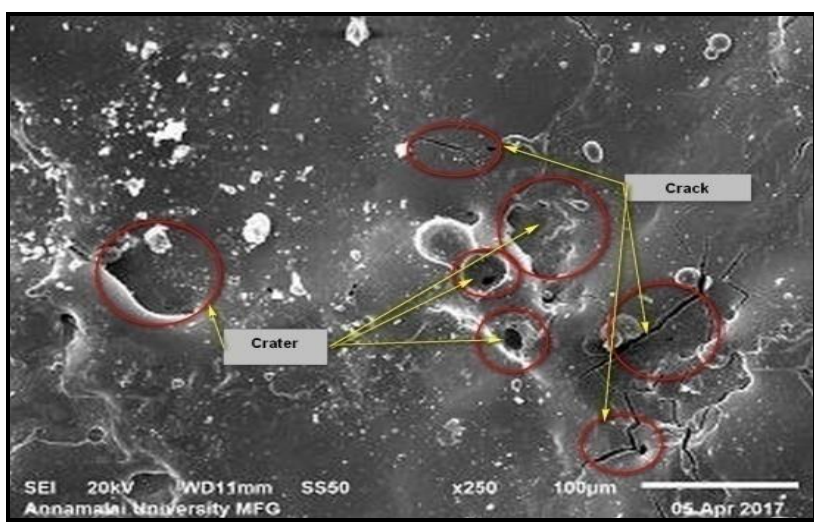

Fig. 14 SEM image for exp. no. 10

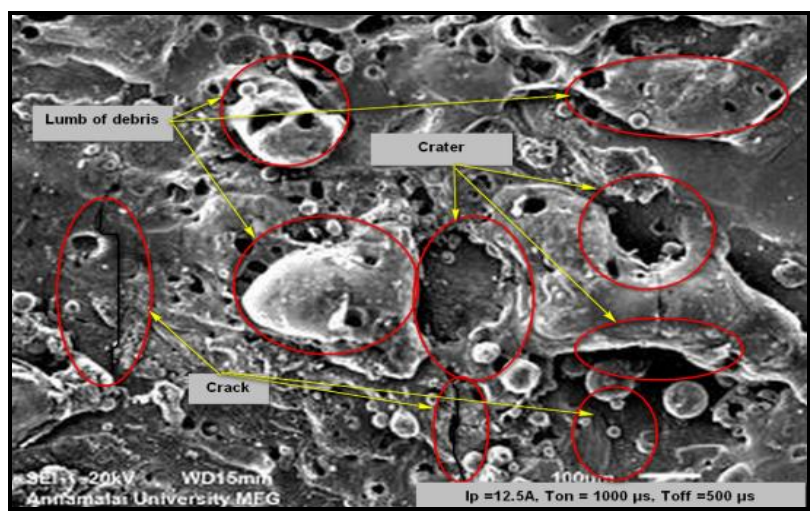

Fig. 15 SEM image for exp. no. 14

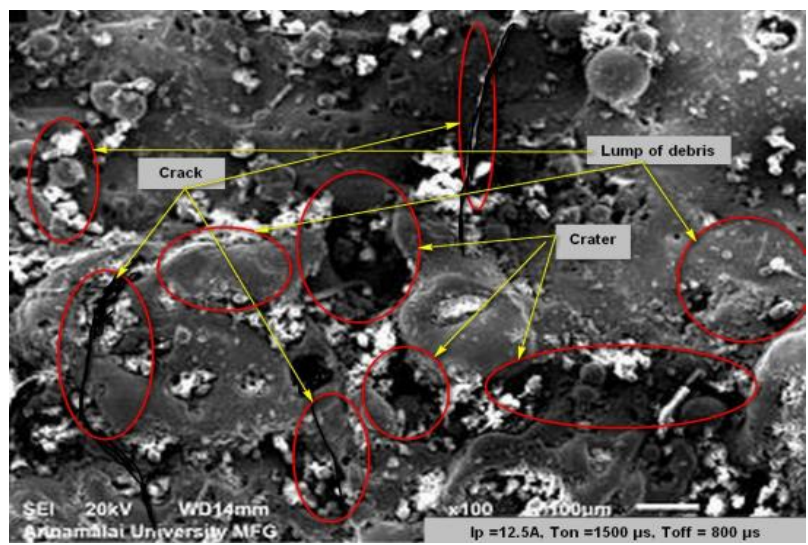

Fig. 16 SEM image for exp. no. 18

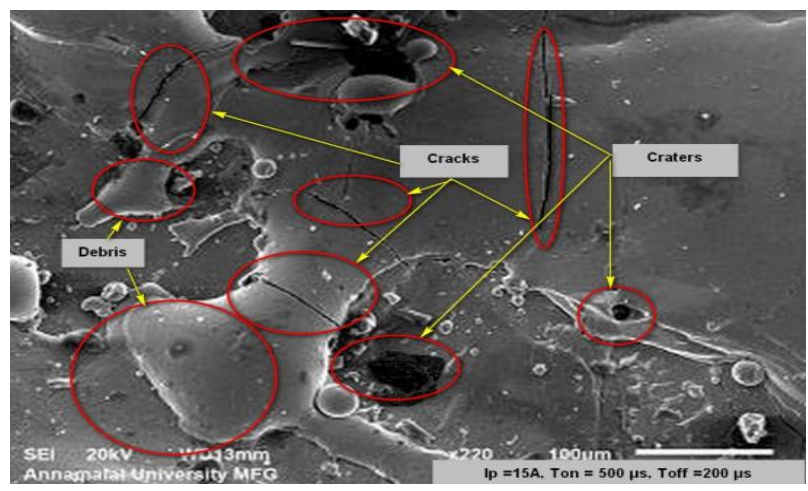

Fig. 17 SEM image for exp. no. 19

Figs. $17-19$ show the micrographs for Experiment Number. $19\left(I_{p}=15 \mathrm{~A}, T_{o n}=500 \mu \mathrm{s}, T_{o f f}=200 \mu \mathrm{s}\right)$, Experiment Number. $23\left(I_{p}=15 \mathrm{~A}, T_{o n}=1000 \mu \mathrm{s}, T_{o f f}=\right.$ $=500 \mu \mathrm{s})$ and Experiment Number. $27\left(I_{p}=15 \mathrm{~A}, T_{\text {on }}=\right.$ $\left.=1500 \mu \mathrm{s}, T_{\text {off }}=800 \mu \mathrm{s}\right)$ respectively. With an increase in 
$I_{p}$ high thermal energy is supplied to the drilling area, hence melting and vaporization occur, causing the formation of a crater in the drilling surface [20]. Pulse-off time found insignificant in the study.

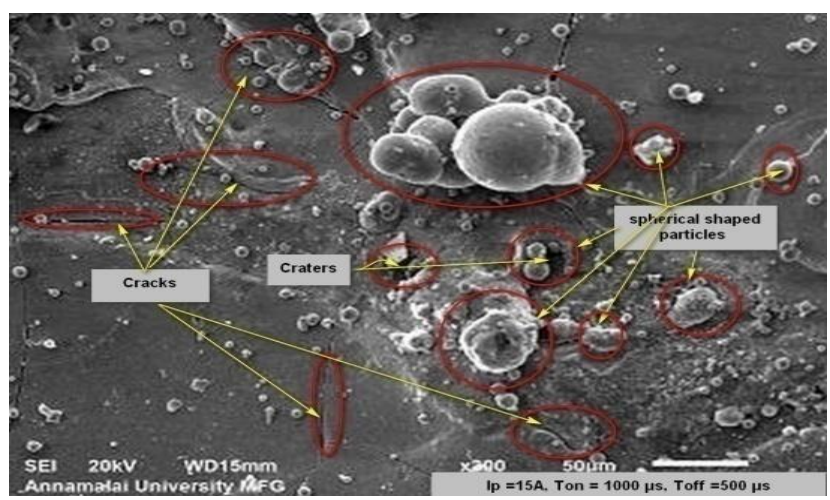

Fig. 18 SEM image for exp. no. 23

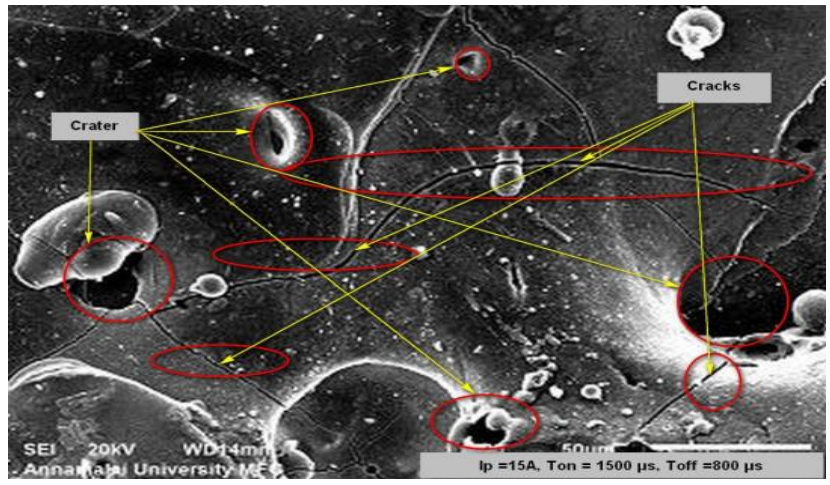

Fig. 19 SEM image for exp. no. 27

\section{Conclusion}

An investigation into Inconel 718 with the help of an Electrical Discharge Drilling process using a hollow copper electrode under the Tungsten powder mixed dielectric medium is presented. The following conclusions are taken from the findings:

1. The MRR value ranged from 0.134 to $0.872 \mathrm{~g} / \mathrm{min}$. and the SR value ranged from 2.508 to $4.578 \mu \mathrm{m}$ when $3 \mathrm{gm} / \mathrm{l}$. of W-powder was introduced.

2. While the peak current increased, the MRR increased, but the MRR decreased as the pulse-off time decreased. At $15 \mathrm{~A}$ of peak current, the maximum MRR was $0.872 \mathrm{~g} / \mathrm{min}$, and the lowest MRR of $0.134 \mathrm{~g} / \mathrm{min}$ was obtained at $200 \mu$ s pulse-off time.

3. The SR increased as the peak current and pulse-on time increased, but decreased as the pulse-off time increased. At $15 \mathrm{~A}$ of peak current and $500 \mu$ s of pulse-on time, the highest SR value of $4.578 \mu \mathrm{m}$ was recorded, while the lowest SR of $2.508 \mu \mathrm{m}$ was achieved at $800 \mu$ s of pulseoff time.

4. ANOVA was used to create the empirical relationship in order to identify the important parameters in the drilling process. When the mathematical model values were compared with experimental values, it was found to be in close agreement to the amount of $90 \%$. According to ANOVA, $I_{p}(55.2 \%)$ on MRR, while $T_{o n}(51.8 \%)$ on SR were the most influential parameters.

5. To determine the individual and interactive impact of input parameters, surface plots were created and used. Individual and interacting impacts of $I_{p}, T_{o n}$, and $T_{\text {off }}$ were the most significantly impacted input parameters, according to the graphs.

6. It has been established that ANN performs exceptionally well in mapping nonlinear relationships between inputs and outputs. The estimated machining output was compared to the observed machining performance, and a satisfactory match was found.

7. From the ANN predictions, it is clear that the maximum error was 0.072 ; the minimum was -0.031 for the MRR. In the case of SR, the maximum error was 0.213 ; the minimum was -0.284 . It has been observed that the calculated error was within the permissible limit range of $\pm 10 \%$. The obtained results revealed a good relationship between experimentation and ANN predictions.

8. The study also looked at the workpiece surface quality after drilling. The SEM-EDS images revealed that the variables $I_{p}$ and $T_{o n}$ had a considerable impact on the drilling process performance. According to SEM inspection, the inclusion of $\mathrm{W}$-powder results in fewer plucked materials, cracks, crates, and debris.

9. The current research will provide significant assistance to the industries in enhancing the quality of the Inconel 718 superalloy drilling.

\section{References}

1. Kuppan, P.; Rajadurai, A.; Narayanan, S. 2008. Influence of EDM process parameters in deep hole drilling of Inconel 718, Journal of Expert Systems with Applications 34(3): 2129-2139. https://doi.org/ 10.1007/s00170-007-1084-y.

2. Lotfi, M.; Amini, S.; Teimouri, R.; Alinaghian, M. 2017. Built-up edge reduction in the drilling of AISI 1045 steel, Materials and Manufacturing Processes 32(6): $623-630$. https://doi.org/10.1080/10426914.2016.1221104.

3. Mount, A. R.; Clifton, D.; Howarth, P.; Sherlock, A. 2003. An integrated strategy for materials characterization and process simulation in electrochemical machining, Journal of Materials Processing Technology 138: $449-454$. https://doi.org/10.1016/S0924-0136(03)00115-8.

4. Jeswani, M. L. 1979. Small hole drilling in EDM, International Journal of Machine Tool Design \& Research 19: 165-169. https://doi.org/10.1016/0020-7357(79)90006-4.

5. Tay, F.; Haider, E. A. 2001. The potential of plating techniques in the development of rapid EDM tooling, Journal of Advanced Manufacturing Technology 18: 892-896.

6. Laxman, J.; Raj Guru, K. 2014. Optimization of EDM process parameters on titanium super alloys based on the grey relational analysis, International Journal of Engineering Research 3(5): 344-348.

7. Mohanty, C. P.; Mahapatra, S. S.; Singh, M. R. 2014. An experimental investigation of machinability of inconel 718 in electrical discharge machining, Procedia Materials Science 6: 605-611. https://doi.org/10.1016/j.mspro.2014.07.075.

8. Jeevamalar, J.; Ramabalan, S.; Senthilkumar, C. 2019. Multi-criteria decision of W-powder mixed electro discharge drilling parameters using TOPSIS Approach, Mechanika 25(1): 52-56. 
https://doi.org/10.5755/j01.mech.25.1.22883.

9. Li, L.; Li, Z.Y.; Wei, X.T.; Cheng, X. 2015. Machining characteristics of Inconel 718 by sinking-EDM and wire-EDM, Materials and Manufacturing Processes 30(8): 968 - 973. https://doi.org/10.1080/10426914.2014.973579.

10. Soni, J. S.; Chakraverti, G. 1994. Machining characteristics of titanium with rotary electro-discharge machining, Wear 17: 51-58.

11. Chow, H. M.; Yan, B. H.; Huang, F. Y. 1999. Micro slit machining using electro-discharge machining with a modified rotary disk electrode (RDE), Journal of Material Processing Technology 91(3): 161-166. https://doi.org/10.1016/S0924-0136(98)00435-X.

12. Yan, B. H.; Wang, C. C.; Chow, H. M.; Lin, Y. C. 2000. Feasibility study of rotary electrical discharge machining with ball burnishing for Al2O3/6061Al composite, Int. Machine Tool Manufacturing 40(10): 1403-1421. https://doi.org/10.1016/S0890-6955(00)00005-5.

13. Mohan, B.: Rajadurai, A.; Satyanarayana, K. G. 2004. Electric discharge machining of $\mathrm{Al}-\mathrm{SiC}$ metal matrix composites using rotary tube electrode, Journal of Materials Processing Technology 153: 978-985.

14. Wick, C. 1980. Programable controlled rotary EDM slashes manufacturing time by $30 \%$, Manufacturing Engineering 84(2): 84-85.

15. Jeevamalar, J.; Ramabalan, S.; Senthilkumar, C. 2020. Modelling of rotary EDM process parameters of Inconel 718 using artificial neural networks, Mechanika 26(6): 540-544.

https://doi.org/10.5755/j01.mech.26.6.20484.

16. Freeman, J. A.; Kapura, D. M. 1992. Neural networks: algorithms, applications, and programming techniques, Addison-Wesley Publishing Company: USA.

17. Mandal, S.; Sivaprasad, P. V.; Venugopal, S.; Murthy, K. P. N. 2009. Artificial neural network modelling to evaluate and predict the deformation behavior of stainless steel type AISI 304L during hot torsion, Applied Soft Computing Journal 9(1): 237-244. https://doi.org/10.1016/j.asoc.2008.03.016.

18. Kumar, S.; Singh, R.; Batish, A.; Singh, T. P. 2015. Study the surface characteristics of cryogenically treated tool-electrodes in powder mixed electric discharge machining process, Material Science Forum 808: 1933.

19. Kumar, A.; Kumar, V.; Kumar, J. 2013. Multiresponse optimization of process parameters based on response surface methodology for pure titanium using WEDM process, International Journal of Advanced Manufacturing Technology 10: 4861-4869.

https://doi.org/10.1007/s00170-013-4861-9.

20. Kolli, M.; Kumar, A. 2015. Effect of dielectric fluid with surfactant and graphite powder on electrical discharge machining of titanium alloy using Taguchi method, Engineering, Science and Technology - An International Journal 18: 524-535.

https://doi.org/10.1016/j.jestch.2015.03.009.

J. Jeevamalar, S. Ramabalan, J. Jancirani

ON THE INFLUENCE OF ELECTRICAL DISCHARGE

DRILLING PARAMETERS AND PERFORMANCE

MEASURES OF INCONEL 718 SUPERALLOY - A STUDY

S u m m a r y

In order to achieve higher productivity and product quality, the investigation of machining parameters on Electrical Discharge Drilling and surface characteristic analysis are most critical for manufacturing industries. The intention of this article is to assess the impact on performance matrices including Material Removal Rate, and Surface Roughness of input factors of peak current, pulseon and off duration while drilling with a rotary hollow copper tool on Inconel 718 under Tungsten powder suspended kerosene. Analysis of Variance has been implemented using MINITAB release 18 software to identify the most significant input factors. An Artificial Neural Network was used for validating the experimental results of the drilling process. The additional intention of this research is to discover the significance of influencing input parameters and analyze the quality surface of the workpiece were observed by microscope tests. The experimental results indicated that the peak current and pulse-on period have an effect on the performance of the drilling process considerably.

Keywords: Inconel 718, electrical discharge drilling, ANOVA, material removal, surface roughness, artificial neural networks, scanning electron microscope.

Received March 06, 2020

Accepted December 07, 2021

This article is an Open Access article distributed under the terms and conditions of the Creative Commons Attribution 4.0 (CC BY 4.0) License (http://creativecommons.org/licenses/by/4.0/). 